\title{
The Influence of Family Dog Ownership and Parental Perceived Built Environment Measures on Children's Physical Activity within the Washington, DC Area
}

\author{
Jennifer D. Roberts ${ }^{1}$ * (D), Lindsey Rodkey ${ }^{1}$, Cortney Grisham ${ }^{2}$ and Rashawn Ray ${ }^{3}$ \\ 1 Department of Kinesiology, School of Public Health, University of Maryland, College Park, MD 20742, USA; \\ lmrodkey@umd.edu \\ 2 College of Science and Mathematics, Austin Peay State University, Clarksville, TN 37044, USA; \\ cgrisham1@my.apsu.edu \\ 3 Department of Sociology, University of Maryland, College Park, MD 20742, USA; rjray@umd.edu \\ * Correspondence: jenrob@umd.edu; Tel./Fax: +1-(301)-405-7748
}

Received: 17 October 2017; Accepted: 14 November 2017; Published: 16 November 2017

\begin{abstract}
Sedentary behavior and physical inactivity are significant contributors to youth obesity in the United States. Neighborhood dog walking is an outlet for physical activity (PA). Therefore, understanding the relationship between built environment, dog ownership, and youth PA is essential. This study examined the influence of dog ownership and parental built environment perceptions on children's PA in the Washington, D.C. area. In 2014, questionnaires were mailed to 2000 parents to assess family dog ownership; children's outdoor dog walking or playing; and parental perceived built environment measures. Chi-square analyses examined differences in parental perceived built environment measures between children with and without family dogs. The sample included 144 children (50\% female; average-age 9.7 years; $56.3 \%$ White; 23.7\% African-American; $10.4 \%$ Asian-American; $29.9 \%$ owned dog). Only $13 \%$ and $5.6 \%$ of the children walked or played outdoors with the dog daily, respectively. A significantly greater proportion $(p$-value $<0.05)$ of parents who owned dogs recognized and observed some home built environment measures (e.g., traffic speed on most streets is $30 \mathrm{mph}$ or less) that were PA -promoting for their children. Findings suggest that dog ownership may provide more positive parental perceptions of the neighborhood built environment, which supports children's outdoor PA through dog walking and playing.
\end{abstract}

Keywords: dog ownership; physical activity; parental perception; built environment

\section{Introduction}

Sedentary behavior and physical inactivity are significant contributors to obesity in the United States. The Centers for Disease Control and Prevention reports that 36.5\% of U.S. adults and $17 \%$ of youth have obesity [1]. Engaging in daily physical activity (PA), such as recreational sports and leisure activities including biking, jogging, and dog walking, can help combat obesity. Dog walking is a unique outlet for PA, considering that one-third of U.S. households are dog owners [2]. One of the first research studies that reported the health benefits of pet ownership was published out of the University of Cambridge over 25 years ago [3]. Since that time, nearly two dozen empirical studies examining the relationship between dog walking and PA have been published in the U.S. However, this entire body of research has focused on adults, with the exception of two studies that explored this relationship among adolescents 12 years of age and older, and one study among children 4-10 years of age [4-6]. Among these two U.S.-based studies in adolescents, it was found that dog ownership was associated with more PA among adolescents by way of walking or playing with the dog $[4,5]$. Likewise, 
in the one and only U.S.-based study in younger children, a higher level of child-dog attachment was found to be associated with a higher level of PA [6].

Research on adolescent PA and dog ownership performed outside the U.S. has reported mixed results. Specifically, in metropolitan Perth and nonmetropolitan regions in Western Australia, observational conclusions revealed that adolescents who walked or played with their dog spent an average of one hour per week on each activity and were significantly more likely to meet national PA recommendations when compared to adolescents who did not engage in these activities [7]. Yet, in the United Kingdom, no evidence was found to support a relationship between objectively measured adolescent PA, specifically dog walking, and dog ownership [8].

Other research on preadolescent PA and dog ownership performed outside the U.S. has reported more positive than negative results. When a preadolescent population of youth was observed in Melbourne, Australia, researchers detected an association between dog ownership and an increase in PA amounting to an additional 29 min per week among girls 5-6 years old and 59 more minutes in girls 10-12 years old [9]. Another cross-sectional Australian study observed similar positive associations between dog ownership and PA among children 10-12 years old [10]. Dog-owning children 9-10 years old from the Liverpool SportsLinx Project engaged in dog walking several times a week more compared to children without a dog [11]. Another study conducted in the United Kingdom found that children 9-10 years of age with a dog spent more time engaging in light and vigorous PA and recorded higher levels of PA counts per minute with by ActiGraph GT1M activity monitors than those without dogs [12]. This study also revealed that dog ownership was $22 \%$ more common in White European households than all other ethnicities included in the study [12]. The dog walkers among a population of 10-12-year-old children in Perth, Australia were more independently mobile and walked or played in the neighborhood, street, and yard at a significantly higher frequency when compared to the non-dog walkers, even though dog walk status was not found to be significantly associated with overall PA, walking, or pedometer steps [13]. Furthermore, subsequent analyses of the children 9-10 years old from the previously mentioned Liverpool SportsLinx Project failed to find evidence that children who live or walk with dogs are fitter or less likely to be obese than children who do not live or walk with dogs [14].

Dog ownership and walking has also been demonstrated to increase independent mobility and decrease anxiety levels in children. Given the research gaps that exist on youth dog ownership and youth dog walking as it correlates to youth PA, it is essential to understand the influence of built environment variables. One U.S.-based study, referenced previously, indicated that adolescents who lived in objectively walkable neighborhoods (e.g., lower perceived traffic safety, higher street connectivity, and less mixed use) were more likely to walk their dog [4]. This finding suggests that dog ownership and one's perceived and objectively measured built environment may influence youth PA. With the majority of literature investigating the relationship between dog ownership and youth PA occurring outside of the U.S., there is a need to further analyze this association within the U.S., particularly among a sample of diverse preadolescent youth. Our study addressed this research gap and examined the influence of family dog ownership and parental built environment perceptions on PA behaviors among Washington, D.C. metropolitan (DMV) children.

\section{Materials and Methods}

\subsection{Design and Sample}

The Built Environment and Active Play (BEAP) Study questionnaire was mailed in September-December 2014 using a stratified sampling strategy to 2000 parents of children (7-12 years) living within nine DMV counties and cities (Washington, DC (District of Columbia); Fairfax County, Virginia (VA); Arlington County, VA; Loudon County, VA; Fairfax City, VA; Alexandria City, VA; Montgomery County, Maryland (MD); Prince George's County, MD; and Frederick County, MD). The BEAP Study area map has been previously published [15]. 
All participants received the BEAP Study questionnaire, a \$10 gift card, and a postage-paid self-addressed envelope with return instructions. If participants preferred to complete an online version of the questionnaire via Qualtrics.com, a secure and encrypted web address and unique access code were provided. Reminder and/or thank you post cards were mailed to the participants seven days after the initial mailing. Adapted from the Neighborhood Impact on Kids project survey, the BEAP Study questionnaire, a confidential study instrument, underwent several iterations of reliability and validity testing [15-17]. Within the questionnaire, several topic areas of questions such as child active play, active transportation, home and neighborhood built environment features, dog ownership, parental rules, demographics, and pre-existing health conditions were captured. An initial response rate of $10 \%$ was obtained, however, approximately 50 incomplete questionnaires were omitted from analysis. The final sample included 144 children. Implicit informed consent was obtained through the return of the completed questionnaire. The Institutional Review Board at The University of Maryland at College Park approved the study protocol (UMCP, 774586-1).

\subsection{Built Environment Variables}

Home was defined as the "home in which you and your child live" as well as the confirmed address to which the BEAP Study questionnaire was mail delivered. The questionnaire further defined home neighborhood as the area "within walking distance" or a "10-15 min walk from your home". The three statement requests that were used to assess parental perceptions of the home neighborhood built environment and walkability were as follows: (1) "Please mark the answer that best applies to you and your child's neighborhood"; (2) "My child can walk or bike to the closest local park or playground (alone or with someone) because: ... "; and (3) "It is difficult for my child to be active in our home neighborhood because: ... ". These three statement requests contained 44 subpart-responses in the form of statements or justifications (e.g., because there are sidewalks; because other children walk or bike) based on a four-point Likert scale of agreement, which were dichotomized and collapsed into "agree" and "disagree" responses. Additionally, parents were asked "Have you been the victim of a crime in your neighborhood?" and "Do you know someone who has been the victim of a crime in your neighborhood?", which both elicited yes/no responses. A final question was included, "About how long would it take you to walk from your/your child's home to each of the nearest places listed below?" This question contained 17 subpart-destinations (e.g., indoor recreation or exercise facility) with responses ranging from 1-5, 6-10, 11-20, 21-30, and over $30 \mathrm{~min}$ that were then dichotomized into "1-10 $\mathrm{min}^{\prime}$ and "over $10 \mathrm{~min}$ ".

\subsection{Dog Ownership Variables}

Three questions were presented regarding family dog ownership, children walking the family dog, and children playing with the family dog. Parents were asked the binary question "Is there a dog in your home/child's home?" If the parents responded yes to this question, they were then asked "How many days per week did your child spend walking your dog last week (including with a parent)?" and "How many days per week did your child spend playing outside with your dog last week (not including walking)?" These last two questions contained responses ranging from 1, 2, 3, 4, 5, 6 , and 7 days.

\subsection{Statistical Analysis}

The Chi-square $\left(\chi^{2}\right)$ Test of Independence was used to determine the independence or relationship of variables $\left(\mathrm{H}_{\mathrm{O}}=\right.$ There is no relationship between the two categorical variables). Hence, the differences in parental perceived built environment measures between children with and without family dogs were examined. Statistical analyses were carried out using STATA/MP 14.1 (College Station, TX, USA). 


\section{Results}

The average age of the 144 children included in the BEAP Study population was 9.7 years $(\mathrm{SD}=1.6)$. White children accounted for about half of the study population $(56.3 \%)$, with African American (23.7\%) and Asian American (10.4\%) following as the highest represented groups. Based on parent-reported weights and heights, $25 \%$ of the children were classified as either overweight or obese. Approximately half (53\%) of the participants were reported to live in households with an annual income greater than $\$ 100,000$, but $14.7 \%$ of the subjects lived in households with an annual income less than $\$ 50,000$.

Among our study population, nearly $30 \%$ of the children lived in a household where there was also a family dog present, and of those children, all of them had parents with some college education or more (Table 1). The majority of dog owners were White (69.1\%), compared to African American (14.3\%), Other (9.5\%), Asian American (7.1\%), and Hispanic/Latino (4.7\%) dog owners. Only 13\% and $5.6 \%$ of the children walked and played outside with the dog daily, respectively (Figures 1 and 2), and among these children, all of them were in first through fourth grades.

Table 1. Built environment and active play (BEAP) study child participant demographics.

\begin{tabular}{|c|c|c|c|c|c|}
\hline Parameter & $\begin{array}{l}\text { Total } \\
n(\%)\end{array}$ & $\begin{array}{c}\text { No } \\
\text { Own Dog } \\
n(\%)\end{array}$ & $\begin{array}{c}\text { Yes } \\
\text { Own Dog } \\
n(\%)\end{array}$ & $\begin{array}{c}\text { Daily Outdoor } \\
\text { Dog Walking- } \\
n(\%)\end{array}$ & $\begin{array}{c}\text { Daily Outdoor } \\
\text { Dog Playing- } \\
n(\%)\end{array}$ \\
\hline \multicolumn{6}{|l|}{ Gender } \\
\hline Male & $72(50.0)$ & $48(47.5)$ & $24(55.8)$ & $2(28.6)$ & 0 \\
\hline Female & $72(50.0)$ & $53(52.8)$ & $19(44.2)$ & $5(71.43)$ & $3(100.0)$ \\
\hline \multicolumn{6}{|l|}{ Ethnicity/Race } \\
\hline Hispanic/Latino & $7(4.9)$ & $5(5.1)$ & $2(4.7)$ & 0 & 0 \\
\hline African American & $32(23.7)$ & $26(28.0)$ & $6(14.3)$ & $3(42.9)$ & $1(33.3)$ \\
\hline American Indian/Alaska Native & $1(0.7)$ & $1(1.1)$ & 0 & 0 & 0 \\
\hline Asian American & $14(10.4)$ & $11(11.8)$ & $3(7.1)$ & 0 & 0 \\
\hline White & $76(56.3)$ & $47(50.5)$ & $29(69.1)$ & $4(57.1)$ & $2(66.7)$ \\
\hline Other & $12(8.9)$ & $8(8.6)$ & $4(9.5)$ & 0 & 0 \\
\hline \multicolumn{6}{|l|}{ Highest Grade Completed } \\
\hline 1st Grade & $14(9.8)$ & $10(10.0)$ & $4(9.3)$ & $2(28.6)$ & $1(33.3)$ \\
\hline 2nd Grade & $24(16.8)$ & $17(17.0)$ & $7(16.3)$ & $2(28.6)$ & 0 \\
\hline 3rd Grade & $21(14.7)$ & $17(17.0)$ & $4(9.3)$ & $1(14.3)$ & 0 \\
\hline 4th Grade & $24(16.8)$ & $12(12.0)$ & $12(27.9)$ & $2(28.6)$ & $2(66.7)$ \\
\hline 5th Grade & $34(23.8)$ & $28(28.0)$ & $6(14.0)$ & 0 & 0 \\
\hline 6th Grade & $17(11.9)$ & $9(9.0)$ & $8(18.6)$ & 0 & 0 \\
\hline$>6$ th Grade & $9(6.3)$ & $7(7.0)$ & $2(4.7)$ & 0 & 0 \\
\hline \multicolumn{6}{|l|}{ Annual Household Income } \\
\hline$\leq \$ 30,000$ & $6(4.4)$ & $4(4.2)$ & $2(4.9)$ & $1(16.7)$ & $1(33.3)$ \\
\hline$\$ 30,001-\$ 50,000$ & $14(10.3)$ & $13(13.7)$ & $1(2.4)$ & 0 & 0 \\
\hline$\$ 50,001-\$ 75,000$ & $12(8.8)$ & $7(7.4)$ & $5(12.2)$ & 0 & 0 \\
\hline$\$ 75,001-\$ 100,000$ & $20(14.7)$ & $13(13.7)$ & $7(17.1)$ & $2(33.3)$ & $1(33.3)$ \\
\hline$\$ 100,001-\$ 150,000$ & 27 (19.9) & $21(22.1)$ & $6(14.6)$ & 0 & 0 \\
\hline$\$ 150,001-\$ 250,000$ & $29(21.3)$ & $18(19.0)$ & $11(26.8)$ & $2(33.3)$ & $1(33.3)$ \\
\hline$\$ 250,001-\$ 500,000$ & $13(9.6)$ & $9(9.5)$ & $4(9.8)$ & $1(16.7)$ & 0 \\
\hline$>\$ 500,000$ & $3(2.2)$ & $2(2.1)$ & $1(2.4)$ & 0 & 0 \\
\hline \multicolumn{6}{|l|}{ Parent Education } \\
\hline Some High School & $1(0.7)$ & $1(1.0)$ & 0 & 0 & 0 \\
\hline Completed High School & $7(4.9)$ & $6(6.1)$ & $1(2.3)$ & 0 & 0 \\
\hline Some College & $31(21.8)$ & $22(22.2)$ & $9(20.9)$ & $2(28.6)$ & $2(66.7)$ \\
\hline Completed College & $47(33.1)$ & $32(32.3)$ & $15(34.9)$ & $2(28.6)$ & 0 \\
\hline Completed Graduate School & $56(39.4)$ & $38(38.4)$ & $18(41.9)$ & $3(42.9)$ & $1(33.3)$ \\
\hline
\end{tabular}


Table 1. Cont

\begin{tabular}{|c|c|c|c|c|c|}
\hline Parameter & $\begin{array}{l}\text { Total } \\
n(\%)\end{array}$ & $\begin{array}{c}\text { No } \\
\text { Own Dog } \\
n(\%)\end{array}$ & $\begin{array}{c}\text { Yes } \\
\text { Own Dog } \\
n(\%)\end{array}$ & $\begin{array}{c}\text { Daily Outdoor } \\
\text { Dog Walking- } \\
n(\%)\end{array}$ & $\begin{array}{c}\text { Daily Outdoor } \\
\text { Dog Playing- } \\
n(\%)\end{array}$ \\
\hline \multicolumn{6}{|l|}{ Doctor Diagnosed Illness } \\
\hline Anxiety & $9(6.5)$ & $4(4.1)$ & $5(12.2)$ & 0 & 0 \\
\hline Asthma & $25(17.6)$ & $19(18.8)$ & $6(14.6)$ & $2(33.3)$ & 0 \\
\hline ADHD/ADD & $17(12.0)$ & $10(10.0)$ & $7(16.7)$ & $1(14.3)$ & 0 \\
\hline High Blood Pressure & $1(0.7)$ & 0 & $1(2.4)$ & 0 & 0 \\
\hline High Cholesterol & $3(2.1)$ & $2(2.0)$ & $1(2.4)$ & $1(16.7)$ & $1(33.3)$ \\
\hline Overweight/Obese & $11(7.9)$ & $9(9.1)$ & $2(5.0)$ & 0 & 0 \\
\hline \multicolumn{6}{|l|}{ Child Weight Status * } \\
\hline Underweight & $12(13.3)$ & $7(10.6)$ & $5(20.8)$ & 0 & 0 \\
\hline Yes & $134(95.0)$ & $93(93.9)$ & $41(97.6)$ & $6(100.0)$ & $2(66.7)$ \\
\hline No & $7(5.0)$ & $6(6.1)$ & $1(2.4)$ & 0 & $1(33.3)$ \\
\hline \multicolumn{6}{|l|}{ County Residence } \\
\hline Montgomery County & $38(27.1)$ & $27(27.6)$ & $11(26.2)$ & $3(42.9)$ & $1(33.3)$ \\
\hline Fairfax County & $39(27.9)$ & $29(29.6)$ & $10(23.8)$ & $1(14.3)$ & 0 \\
\hline Loudoun County & $19(13.6)$ & $10(10.2)$ & $9(21.4)$ & $1(14.3)$ & 0 \\
\hline Prince George's County & $20(14.3)$ & $16(16.3)$ & $4(9.5)$ & $1(14.3)$ & 0 \\
\hline Frederick County & $10(7.1)$ & $7(7.1)$ & $3(7.1)$ & 0 & $1(33.3)$ \\
\hline Washington, DC & $14(10.0)$ & $9(9.2)$ & 5 (11.9) & $1(14.3)$ & $1(33.3)$ \\
\hline
\end{tabular}

* Child Weight Status calculated based on parent-reported child weight and height, and weight classifications were based on Centers for Disease Control and Prevention BMI-for-age weight status categories.

Chi-square $\left(\chi^{2}\right)$ analysis was used to determine the differences in home built environment measures by dog ownership (Table 2). The majority of dog owners lived in single family homes $(72.1 \%)$, compared to only $4.7 \%$ of dog owners residing in apartments. However, the majority of families that did not own a dog also lived in single family homes (61.4\%). The distribution of front yard and back yard space is almost equal when comparing dog ownership. There were no statistically significant differences in home built environment features between families with dogs and families without dogs.

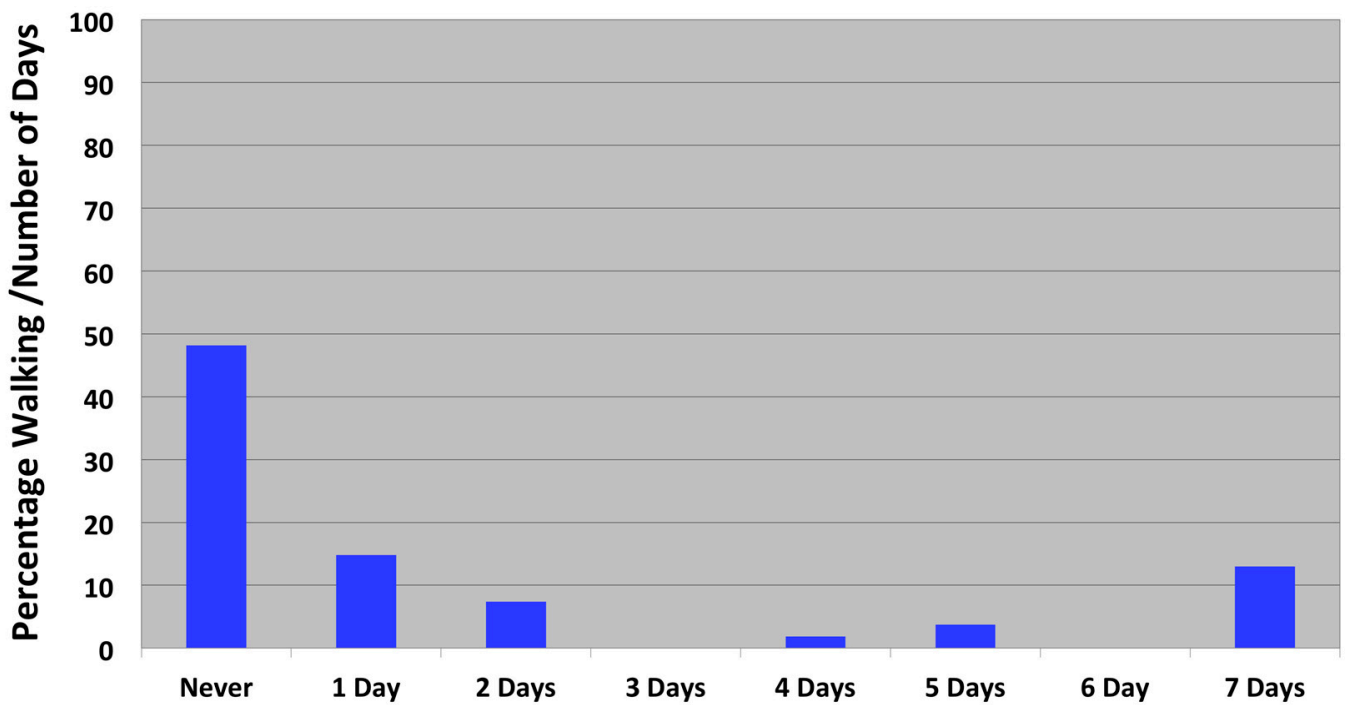

Figure 1. Frequency of children walking outdoors with family dog. 


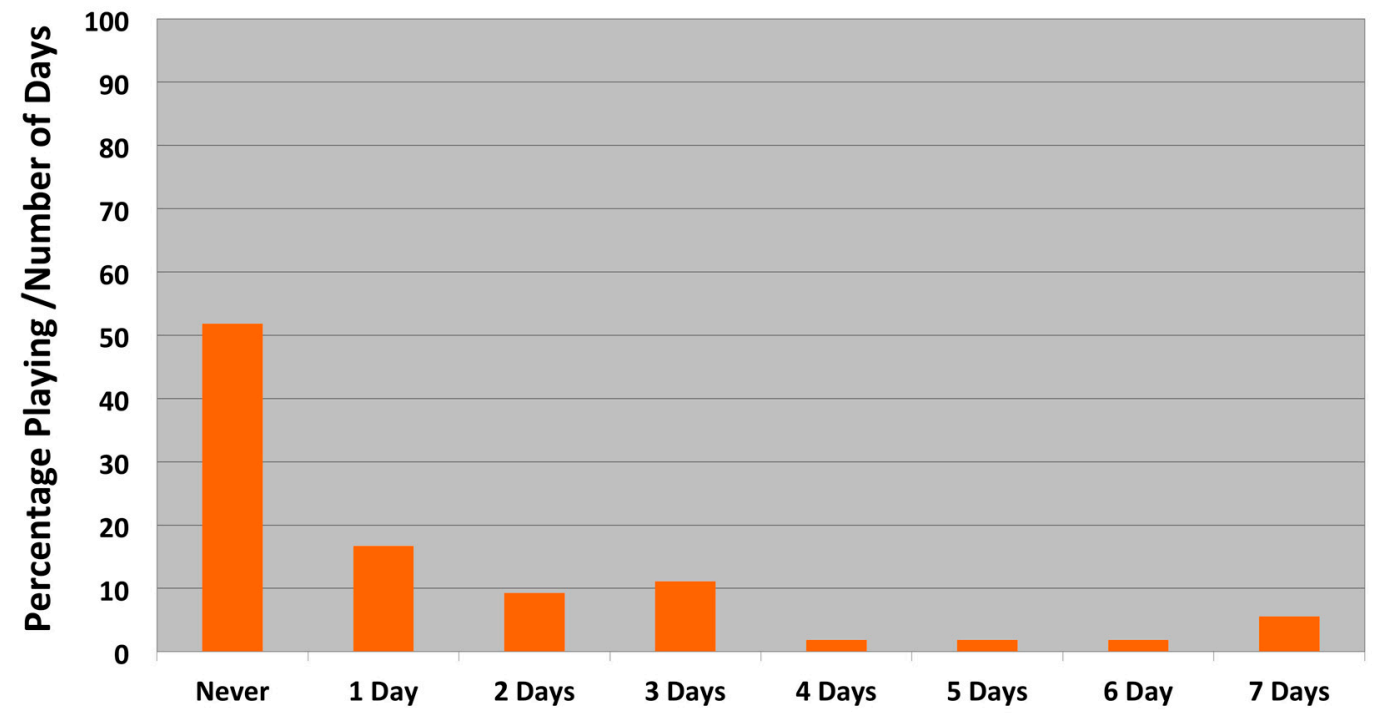

Figure 2. Frequency of children playing outdoors with family dog.

Table 2. Differences in home built environment measures by family dog ownership.

\begin{tabular}{ccccc}
\hline Destinations within 1-10 Min Walk of Home & $\begin{array}{c}\text { Yes } \\
\text { Dog (\%) }\end{array}$ & $\begin{array}{c}\text { No } \\
\text { Dog (\%) }\end{array}$ & $\boldsymbol{\chi}^{\mathbf{2}}$ & $p_{\text {-Value }}{ }^{\circ}$ \\
\hline $\begin{array}{c}\text { Home Type } \\
\text { Single Family Home }\end{array}$ & 72.1 & 61.4 & 3.0 & $0.400^{\Delta}$ \\
Townhouse & 23.3 & 24.8 & & \\
Apartment & 4.7 & 12.9 & & \\
Other & 0 & 1.0 & & \\
Front Yard & 83.7 & 82.2 & 0.050 & 0.823 \\
Back Yard & 83.7 & 80.0 & 0.272 & 0.602 \\
Side Yard & 60.5 & 52.5 & 0.763 & 0.382 \\
Driveway & 72.1 & 67.0 & 0.362 & 0.548 \\
Home Street Sidewalks & 72.4 & 76.2 & 0.054 & 0.816 \\
Neighborhood Sidewalks & 76.7 & 83.2 & 0.817 & 0.366 \\
Home Ownership & & & 2.5 & 0.293 \\
Own & 72.1 & 72.3 & & \\
Rent & 20.9 & 25.7 & & \\
Home Street Dead End/Cul-de-sac & 30.2 & 34.6 & 0.265 & 0.607 \\
\hline
\end{tabular}

$\bigcirc 1$ Degree of freedom unless noted otherwise; ${ }^{\Delta} 3$ Degrees of freedom.

Differences in parental perceived built environment measures by dog ownership were also examined (Table 3$)$. A significantly greater proportion $(p$-value $<0.05)$ of parents who owned dogs recognized and observed some home built environment measures that were PA-promoting for their children. Specifically, more parents who owned dogs agreed (strongly agree + agree) with built environment statements representing positive perceptions of some built environment features (e.g., neighborhood esthetics, safety, walkability infrastructure, and distance) as compared to the parents of children without dogs. For example, a greater proportion of dog owner parents (83.3\%) agreed with the built environment measure representing their neighborhood walkability and safety, which stated that "The speed of traffic on most streets is usually $30 \mathrm{mph}$ or less" compared to non-dog owner parents (67.7\%). Additionally, no dog-owning parents thought that it was difficult for their child to be active in their home neighborhood because of crime, compared to parents who did not own dogs $(10.0 \%)$. While statistical significance was not achieved, only $9.5 \%$ reported that it was likely their child "could be taken or hurt by a stranger" in their neighborhood as compared to the perceptions of $22.8 \%$ of non-dog owners. 
Table 3. Differences in perceived built environment measures by family dog ownership.

\begin{tabular}{|c|c|c|c|c|}
\hline Built Environment Measure & $\begin{array}{c}\text { Yes } \\
\text { Dog Agree (\%) }\end{array}$ & $\begin{array}{c}\text { No } \\
\text { Dog Agree (\%) }\end{array}$ & $x^{2}$ & $p$-Value ${ }^{\circ}$ \\
\hline Many streets in my neighborhood are hilly. & 51.6 & 51.5 & 0.002 & 0.969 \\
\hline There are not any dead end streets. & 21.4 & 24.0 & 0.110 & 0.741 \\
\hline \multirow{2}{*}{$\begin{array}{l}\text { Sidewalks are on most streets. } \\
\text { Usually sidewalks are separated from the road/traffic by } \\
\text { parked cars. }\end{array}$} & 76.2 & 82.2 & 0.675 & 0.411 \\
\hline & 43.9 & 61.6 & 3.7 & $0.054^{*}$ \\
\hline \multirow{8}{*}{$\begin{array}{l}\text { Trees are along the streets. } \\
\text { My child can look at many interesting things while walking. } \\
\text { There are many natural things for my child to see. } \\
\text { Many buildings/homes are present for my child to see. } \\
\text { The traffic makes it difficult or unsafe for my child to walk. } \\
\text { The speed of traffic on most streets is usually } 30 \text { mph or less. } \\
\text { Most motorist drive faster than the posted speed limits. } \\
\text { Streets have good lighting at night. }\end{array}$} & 88.4 & 89.0 & 0.119 & 0.913 \\
\hline & 81.4 & 77.0 & 0.342 & 0.559 \\
\hline & 81.4 & 86.0 & 0.490 & 0.484 \\
\hline & 83.7 & 82.8 & 0.017 & 0.896 \\
\hline & 27.9 & 41.8 & 2.5 & 0.116 \\
\hline & 83.3 & 67.7 & 3.6 & $0.057^{*}$ \\
\hline & 79.1 & 82.0 & 0.169 & 0.681 \\
\hline & 51.2 & 55.5 & 0.223 & 0.637 \\
\hline $\begin{array}{l}\text { Walkers and bikers can be easily seen by people in } \\
\text { their homes. }\end{array}$ & 72.1 & 72.0 & $<0.001$ & 0.991 \\
\hline \multirow{6}{*}{$\begin{array}{l}\text { Busy streets have crosswalks and signals. } \\
\text { There is a high crime rate. } \\
\text { The streets have a lot of litter. } \\
\text { Many families look like us in our neighborhood. } \\
\text { You have been the victim of a crime in your neighborhood. } \\
\text { You know someone who has been the victim of a crime in } \\
\text { your neighborhood. }\end{array}$} & 72.1 & 71.0 & 0.018 & 0.895 \\
\hline & 11.6 & 18.8 & 1.1 & 0.290 \\
\hline & 14.0 & 13.9 & $<0.001$ & 0.988 \\
\hline & 66.7 & 71.9 & 0.380 & 0.538 \\
\hline & 14.0 & 22.0 & 1.2 & 0.266 \\
\hline & 44.2 & 49.5 & 2.0 & 0.363 \\
\hline \multicolumn{5}{|l|}{ I'm afraid of my child being taken or hurt by . } \\
\hline a known "bad" person (adult or child) in my neighborhood. & 14.0 & 18.0 & 0.353 & 0.553 \\
\hline \multicolumn{5}{|l|}{ It is likely that my child can be taken or hurt by a stranger ... } \\
\hline in my yard, driveway, or common area. & 7.0 & 12.9 & 1.1 & 0.303 \\
\hline \multicolumn{5}{|l|}{ My child can walk or bike to the closest park or playground because } \\
\hline there are sidewalks or bike lanes. & 74.4 & 76.0 & 0.041 & 0.840 \\
\hline the route is simple. & 81.4 & 82.0 & 0.007 & 0.931 \\
\hline the route has good lighting when it's dark outside. & 44.2 & 37.8 & 0.516 & 0.472 \\
\hline there are no dangerous crossings. & 48.8 & 48.5 & 0.002 & 0.969 \\
\hline my child does not get too hot and sweaty. & 51.2 & 54.6 & 0.145 & 0.704 \\
\hline other children walk or bike. & 81.4 & 75.8 & 0.546 & 0.460 \\
\hline it is considered cool to walk or bike. & 61.9 & 63.9 & 0.051 & 0.821 \\
\hline my child does not have much stuff to carry. & 72.1 & 79.6 & 0.958 & 0.328 \\
\hline $\begin{array}{l}\text { it is easier than me driving there on the way to } \\
\text { something else. }\end{array}$ & 52.4 & 40.2 & 1.8 & 0.184 \\
\hline \multirow{2}{*}{$\begin{array}{l}\text { it involves very little planning ahead. } \\
\text { there are areas to leave a bike safely. }\end{array}$} & 69.8 & 67.4 & 0.081 & 0.777 \\
\hline & 60.5 & 57.6 & 0.103 & 0.748 \\
\hline there are no stray dogs. & 76.7 & 62.6 & 2.7 & 0.100 \\
\hline \multirow{2}{*}{$\begin{array}{l}\text { it is not too far. } \\
\text { my child would not have to walk/bike through high crime } \\
\text { or unsafe areas. }\end{array}$} & 83.3 & 83.7 & 0.003 & 0.960 \\
\hline & 81.4 & 73.7 & 0.965 & 0.326 \\
\hline \multicolumn{5}{|c|}{ It is difficult for my child to be active in our home neighborhood because ... } \\
\hline there is no choice of activities. & 19.1 & 17.2 & 0.071 & 0.790 \\
\hline there is no play equipment (e.g., basketball hoop). & 19.1 & 19.0 & $<0.001$ & 0.995 \\
\hline there is no adult supervision. & 24.4 & 24.7 & 0.002 & 0.965 \\
\hline there are no other children there. & 28.6 & 23.0 & 0.494 & 0.482 \\
\hline it is not safe because of crime. & 0 & 10.0 & 4.52 & $0.034^{*}$ \\
\hline it is not safe because of traffic. & 11.9 & 25.3 & 3.14 & 0.077 \\
\hline it does not have good lighting. & 26.2 & 30.3 & 0.242 & 0.623 \\
\hline
\end{tabular}

$\bigcirc$ Degree of freedom unless noted otherwise; ${ }^{*}$ Statistically significant $(p$-value $<0.05)$.

When parents were asked to estimate the time it would take for them to walk from their home to the nearest destinations, there was no statistically significant difference of parental perception between dog owners and non-dog owners (Table 4). However, there were a few destinations that were found to be moderately different. It was found that there were less parents of children with dogs $(9.5 \%)$ who perceived the distance to a fast food restaurant as a 10-min or less walk from their home, compared to the parents of children without dogs (26.0\%). More dog owners $(65.9 \%)$ perceived 
biking/hiking/walking trails and paths were a 10-min or less walk from their home, compared to non-dog owners (50.0\%). Additionally, more dog owners (69.8\%) compared to non-dog owners (57.3\%) perceived public open space within a 10-min walk from their house.

Table 4. Differences in parental perceived walking time by family dog ownership.

\begin{tabular}{lcccc}
\hline Destinations within 1-10 Min Walk of Home & $\begin{array}{c}\text { Yes } \\
\text { Dog (\%) }\end{array}$ & $\begin{array}{c}\text { No } \\
\text { Dog (\%) }\end{array}$ & $\boldsymbol{\chi}^{\mathbf{2}}$ & $p$-Value \\
\hline Friend's or relative's house & 72.5 & 70.3 & 0.074 & 0.963 \\
Public playground & 64.3 & 71.0 & 0.878 & 0.645 \\
Biking/hiking/walking trails and paths & 65.9 & 50.0 & 3.35 & 0.187 \\
Basketball court & 62.8 & 64.0 & 1.2 & 0.546 \\
Public open space that is not a park & 69.8 & 57.3 & 3.5 & 0.175 \\
Public park & 53.5 & 57.1 & 0.164 & 0.921 \\
Bus or Metro stop & 47.6 & 54.0 & 0.781 & 0.677 \\
Outdoor swimming pool & 48.8 & 33.0 & 4.0 & 0.133 \\
Other playing fields/court (e.g., tennis, softball) & 37.2 & 44.4 & 1.00 & 0.606 \\
School grounds during non-school hours & 48.8 & 42.4 & 0.873 & 0.646 \\
Convenience/corner store & 20.9 & 34.0 & 2.7 & 0.260 \\
Fast food restaurant & 9.5 & 26.0 & 4.9 & 0.088 \\
Indoor recreation or exercise facility (e.g., YMCA) & 11.6 & 10.2 & 0.535 & 0.765 \\
Beach, lake, river or creek & 14.0 & 11.1 & 0.230 & 0.891 \\
Library & 14.3 & 8.1 & 2.5 & 0.291 \\
Ski or other winter recreation area & 0 & 1.0 & 0.440 & 0.802 \\
Indoor swimming pool & 12.2 & 6.0 & 1.6 & 0.457 \\
\hline
\end{tabular}

$\square 2$ Degree of freedom unless noted otherwise.

\section{Discussion}

Our results suggest that dog ownership may provide more positive parental perceptions of the neighborhood built environment, which supports children's outdoor PA through dog walking and playing. Unlike older adolescents or children outside of the U.S. who may experience more independent mobility, we found that parental perceptions of the built environment appear to influence their children's dog-related PA.

Dog-owning parents had fewer perceived safety risks for their child being active in the neighborhood. This may be due to the fact that there is a higher intimacy level within the neighborhood because there is a higher degree of neighborhood engagement with dog walking and playing multiple times per day. Sense of place, including place attachment and place meaning, has been shown to shape the way individuals perceive their neighborhood and this can vary significantly among different individuals within the same neighborhood [18]. Activities, such as dog walking, foster neighborhood bond and intimacy, which ultimately increases place attachment and place meaning in a favorable manner. Parents may also believe that a dog can provide protection for their child and therefore they are less concerned with their child being hurt by a stranger. This may especially be true depending on the dog breed, as was found in the Liverpool SportsLinx Project. In this project, 9-10-year-old children who owned Pit Bulls as opposed to other non-Pit Bull breeds of dogs were more likely to report friends walking with their dog [11]. A general consensus has been reported that larger, louder, and darker dogs, such as Pit Bulls and Dobermans, would be helpful with house and neighborhood security because of their easily recognized physical appearance and reputation as attack- and guard-dogs [19].

Our results suggest that parents and children with dogs may visit different locations compared to those without dogs. For example, since public playgrounds are not appropriate places for dogs, dog owners may prefer open spaces where dogs can run off-leash. This was demonstrated in our research, where more dog owners perceived biking/hiking/walking trails and paths to be a 10-min or less walk from their home compared to non-dog owners. 
There has been a challenge in establishing a causal influence of dog ownership on PA in adults, and this certainly has not been established in adolescents or children. While longitudinal studies in adults have suggested that dog owners become more active, the effect in children remains unknown partly because this research has not been fully explored. Consistent with U.S. households, $30 \%$ of our study population owned dogs and among this sample, all of the parents with the exception of one received some college education or more. Therefore, this more educated population may have underestimated the potential influence of dog ownership on PA since this sample of parents may appreciate the importance of PA for their children, regardless of dog ownership. Furthermore, nearly $70 \%$ of our study population who owned dogs was White, which was similar to previous findings in other research $[4,5,12]$. While non-Whites are much less likely to own pets compared to Whites, the human-dog companionship has also been shown to vary by race and ethnicity $[20,21]$. Among the exceptionally limited research exploring the relationship between ethnic diversity and companion animals, it has been found that various groups of non-Whites were afraid of dogs, disliked the hygienic mannerisms of dogs, or used their dog for personal safety $[20,21]$. Therefore, the motivation for dog ownership may not be founded in reasons of companionship, which may limit the PA interactions of walking or playing for adults and children.

As a strength of this study, to date, this is the first U.S.-based study to explore the relationship of dog ownership and PA among a racially and ethnically diverse population of younger children. A prior U.S.-based study in younger children that did report increased PA with dog ownership consisted of over $97 \%$ White children [6]. However, the current study consisted of less than $60 \%$ White children. In our research, it was found that parental perceptions of the built environment could have a meaningful impact on children's dog-related PA. However, additional research is needed to understand the social and cultural influences of this impact.

As with many studies, this study encountered a few limitations. Specifically, the questionnaire relied on family dog ownership as the primary measure. It is possible that children could walk or play regularly with other dogs in the neighborhood, but this would not be accounted for since the family would not own that dog. The age and type of dog could also impact the daily walking and playing habits for children, as these factors influence the dog's energy levels and frequency of needing outside relief. Furthermore, only outdoor playing was assessed and data on indoor dog playing was not captured in this study. Another important limitation of this study is that the questionnaire only collected data on how many days per week the child walked or played with the dog and it did not ask about the minutes or intensity of the PA. Therefore, dog ownership contribution to daily PA accumulation could not be objectively or subjectively estimated. Additionally, since cross-sectional studies only provide a snap-shot in time, youth PA patterns prior to and during dog ownership could not be established. Again, additional research in this area of study, which would collect both objective and subjective PA, is warranted since dog walking or playing could provide an integral outlet for increasing youth PA.

\section{Conclusions}

This study suggests that dog ownership may positively influence parental perceptions of the neighborhood built environment. This is important because this positive perception may facilitate their children's outdoor PA through dog walking and playing.

Acknowledgments: A Uniformed Services University of the Health Sciences intramural start-up grant and University of Maryland start-up grant for newly appointed faculty provided funding for this study.

Author Contributions: Author contributions are as follows: (1) Conceived and designed the study: Jennifer D. Roberts.; (2) Study design consultation and execution: Jennifer D. Roberts and Rashawn Ray; (3) Quantitative analyses: Jennifer D. Roberts; (4) Manuscript composition: Jennifer D. Roberts, Lindsey Rodkey, Cortney Grisham and Rashawn Ray; Manuscript editing: Jennifer D. Roberts and Rashawn Ray.

Conflicts of Interest: The authors declare no conflict of interest. 


\section{References}

1. Ogden, C.; Carroll, M.; Fryar, C.D.; Flegal, K.M. Prevalence of Obesity Among Adults and Youth: United States, 2011-2014. NCHS Data Brief. 2015, 219, 1-8.

2. American Veterinary Medical Association (AVMA). U.S. Pet Ownership Statistics. Available online: https: / / www.avma.org/KB/Resources/Statistics/Pages/Market-research-statistics-US-pet-ownership.aspx (accessed on 21 September 2016).

3. Serpell, J. Beneficial effects of pet ownership on some aspects of human health and behaviour. J. R. Soc. Med. 1991, 84, 717-720. [PubMed]

4. $\quad$ Engelberg, J.K.; Carlson, J.A.; Conway, T.L.; Cain, K.L.; Saelens, B.E.; Glanz, K.; Frank, L.D.; Sallis, J.F. Dog walking among adolescents: Correlates and contribution to physical activity. Prev. Med. 2016, 82, 65-72. [CrossRef] [PubMed]

5. Sirard, J.R.; Patnode, C.D.; Hearst, M.O.; Laska, M.N. Dog ownership and adolescent physical activity. Am. J. Prev. Med. 2011, 40, 334-337. [CrossRef] [PubMed]

6. Gadomski, A.M.; Scribani, M.B.; Krupa, N.; Jenkins, P. Pet dogs and child physical activity: The role of child-dog attachment. Pediatr. Obes. 2017, 12, e37-e40. [CrossRef] [PubMed]

7. Martin, K.E.; Wood, L.; Christian, H.; Trapp, G.S. Not Just "A Walking the Dog": Dog Walking and Pet Play and Their Association With Recommended Physical Activity Among Adolescents. Am. J. Health Promot. AJHP 2015, 29, 353-356. [CrossRef] [PubMed]

8. Westgarth, C.; Ness, A.R.; Mattocks, C.; Christley, R.M. A Birth Cohort Analysis to Study Dog Walking in Adolescence Shows No Relationship with Objectively Measured Physical Activity. Front. Vet. Sci. 2017, 4, 62. [CrossRef] [PubMed]

9. Salmon, J.; Timperio, A.; Chu, B.; Veitch, J. Dog ownership, dog walking, and children's and parents' physical activity. Res. Q. Exerc. Sport 2010, 81, 264-271. [CrossRef] [PubMed]

10. Christian, H.; Trapp, G.; Lauritsen, C.; Wright, K.; Giles-Corti, B. Understanding the relationship between dog ownership and children's physical activity and sedentary behaviour. Pediatr. Obes. 2013, 8, 392-403. [CrossRef] [PubMed]

11. Westgarth, C.; Boddy, L.M.; Stratton, G.; German, A.J.; Gaskell, R.M.; Coyne, K.P.; Bundred, P.; McCune, S.; Dawson, S. A cross-sectional study of frequency and factors associated with dog walking in 9-10 year old children in Liverpool, UK. BMC Public Health 2013, 13, 822. [CrossRef] [PubMed]

12. Owen, C.G.; Nightingale, C.M.; Rudnicka, A.R.; Ekelund, U.; McMinn, A.M.; van Sluijs, E.M.; Griffin, S.J.; Cook, D.G.; Whincup, P.H. Family dog ownership and levels of physical activity in childhood: Findings from the Child Heart and Health Study in England. Am. J. Public Health 2010, 100, 1669-1671. [CrossRef] [PubMed]

13. Christian, H.; Trapp, G.; Villanueva, K.; Zubrick, S.R.; Koekemoer, R.; Giles-Corti, B. Dog walking is associated with more outdoor play and independent mobility for children. Prev. Med. 2014, 67, 259-263. [CrossRef] [PubMed]

14. Westgarth, C.; Boddy, L.M.; Stratton, G.; German, A.J.; Gaskell, R.M.; Coyne, K.P.; Bundred, P.; McCune, S.; Dawson, $\mathrm{S}$. The association between dog ownership or dog walking and fitness or weight status in childhood. Pediatr. Obes. 2016. [CrossRef] [PubMed]

15. Roberts, J.D.; Ray, R.; Biles, A.D.; Knight, B.; Saelens, B.E. Built environment and active play among Washington DC metropolitan children: A protocol for a cross-sectional study. Arch. Public Health Arch. Belg. Sante Publique 2015, 73, 22. [CrossRef] [PubMed]

16. Neighborhood Impact on Kids (NIK). Neighborhood Impact on Kids (NIK) Surveys—Seattle Children's NIK Project. Available online: http://www.seattlechildrens.org/research/child-health-behavior-anddevelopment/saelens-lab/measures-and-protocols / (accessed on 11 February 2016).

17. Neighborhood Impact on Kids (NIK). Neighborhood Impact on Kids (NIK) Project. Available online: http:/ / www.nikproject.org/About_Us.htm (accessed on 11 February 2016).

18. Kudryavtsev, A.; Stedman, R.C.; Krasny, M.E. Sense of place in environmental education. Environ. Educ. Res. 2012, 18, 229-250. [CrossRef]

19. Austin, D.F. Dogs and Personal Secruity: An Introductory Guide. Available online: http://www4.ncsu.edu/ $\sim$ n51ls801/securitydogs.html (accessed on 8 November 2017). 
20. Sejra, A.; Bavishi, H.; Shah, R.; Behrooz, S.; Fagan, J.M. Animal Companionship and Ethnic Diversity. Available online: https:/ / rucore.libraries.rutgers.edu/rutgers-lib/38326/pdf/1 (accessed on 5 October 2017).

21. Risley-Curtiss, C.; Holley, L.C.; Wolf, S. The animal-human bond and ethnic diversity. Soc. Work 2006, 51, 257-268. [CrossRef] [PubMed] 